\title{
Synthesized peptide 710-725 from HCV subtype 1a E2 glycoprotein blocks HCV infection through competitive binding of CD81
}

\author{
XIAOJING LIU, NA CHEN, SHUMEI LIN and MIN LIU \\ Department of Infectious Diseases, The First Affiliated Hospital, \\ Medical College of Xi'an Jiaotong University, Xi'an, Shaanxi 710061, P.R. China
}

Received August 4, 2015; Accepted January 12, 2016

DOI: $10.3892 /$ ijmm.2016.2459

\begin{abstract}
Hepatitis $\mathrm{C}$ virus (HCV) infection is a significant public health problem worldwide. However, there is still a lack of effective therapeutic drugs which could be used for the interruption of the disease. In the present study, for the first time, we reported that a synthesized peptide, which was synthesized by solid phase peptide synthesis and derived from the amino acids 710 to 725 of the HCV E2, functioned as an inhibitor of $\mathrm{HCV}$ infection. Using an MTT assay, we found that the E2 (710-725) peptide exerted no specific cytotoxicity on Huh7.5 cells and primary human hepatocytes $(\mathrm{pHH})$. Interestingly, E2 (710-725) peptide blocked the entry of cell culture-derived $\mathrm{HCV}$ (HCVcc) into hepatocytes. Moreover, it suppressed HCV RNA replication and $\mathrm{HCV}$-specific protein NS3 and NS5B expression, as shown by western blot analysis. Moreover, E2 (710-725) markedly attenuated the inhibitory effect of HCVcc on hepatocyte viability. Additionally, a co-immuninoprecipitation assay demonstrated that E2 (710-725) abrogated the interaction between CD81 and HCV E2 envelope protein through competitive binding of CD81. Overall, our results revealed that the synthesized peptide E2 (710-725) blocked CD81-mediated HCV entry and possessed the potential to treat HCV infection. Thus, the present study provided novel insights into the development of new drugs for preventing HCV infection.
\end{abstract}

\section{Introduction}

Hepatitis $\mathrm{C}$ virus (HCV) infection has become a global public health problem worldwide: it infects approximately $3 \%$ of the

Correspondence to: Dr Min Liu, Department of Infectious Diseases, The First Affiliated Hospital, Medical College of Xi'an Jiaotong University, 277 Yanta West Road, Xi'an, Shaanxi 710061, P.R. China

E-mail: minliusx@163.com

Key words: hepatitis C virus, hepatitis C virus E2, virus infection, $\mathrm{CD} 81$ population worldwide, which may eventually lead to hepatitis, cirrhosis, and liver cancer (1). HCV, which is a member of the Flaviviridae family, is a positive-stranded RNA with a high infection rate (2). In recent years, with advances in knowledge and technology, treatments for HCV infection have improved to a certain degree $(3,4)$. However, effective and secure therapeutic approaches are still lacking.

The HCV genome encodes a polyprotein of $\sim 3,010$ amino acids, which is processed into core protein $\mathrm{C}$, envelope glycoprotein 1 (E1) and 2 (E2), and non-structural proteins such as non-structural proteins 3 and -5B (NS3 and NS5B) $(5,6)$. Of these proteins, it has been suggested that HCV E2 glycoproteins play an important role in regulating HCV entry (7). E2 is a transmembrane glycoprotein containing the amino acid residues 384-746 that mediates HCV entry through interacting with various surface receptors on hepatic cells, including CD81, low-density lipoprotein receptor, scavenger receptor class B type I (SR-BI), claudin 1, and occludin $(8,9)$. CD81 is the first identified essential HCV receptor that has been extensively studied $(10,11)$. Various studies have suggested that targeting and inhibiting CD81 inhibits HCV infection $(8,12,13)$. Thus, CD81 may be a potential molecular target for developing novel and promising anti-HCV therapies.

It has been suggested that the conserved E2 (502-520) segment plays a critical role in cell entry by influencing interaction with $\mathrm{HCV}$ receptors (14). Antibodies to the E2 (412-423) regions have been reported to play broadly neutralizing roles (15). Mutations of the two conserved histidines (490 and 621) located in E2 have been noted to block the binding of CD81 with the E2 protein (16). Albecka et al have demonstrated that a segment from 705 to 715 located in the stem region of E2 is involved in regulating HCV entry and infection (17).

The use of synthesized peptide to inhibit HCV infection has been widely investigated. It has been suggested that synthetic anti-lipopolysaccharide peptides bind to heparan sulfate moieties on the cell surface and inhibit infection with a variety of enveloped viruses, including HCV (18). Human apolipoprotein E peptides were found to inhibit HCV entry by blocking virus binding (19). Bukong et al reported that a novel human radixin peptide suppressed $\mathrm{HCV}$ infection at the level of cell entry (20). It has previously been noted that synthesized 
peptide $\mathrm{C} 18$ (WPWHNHR) with the highest affinity for binding HCV E2 protein effectively inhibited HCV infection (21).

In the present study, we synthesized a short peptide of E2 (710-725) from the E2 glycoprotein and investigated its effects on HCV infection. The lack of a cell culture system to maintain the effective various replications has been a major obstacle for studying HCV. Usage of the developed cell culture-derived $\mathrm{HCV}$ ( $\mathrm{HCVcc}$ ) has become a reliable system for investigating HCV replication and infection $(6,22,23)$. We evaluated the possible role of the synthesized peptide E2 (710725 ) in HCV infection by using HCVcc. Our results showed that treatment with E2 (710-725) dose-dependently decreased HCVcc entry, RNA replication, and protein expression in hepatocytes. Furthermore, the inhibitory effect of HCVcc on hepatocyte viability was reversed by the synthesized peptide E2 (710-725). Using a co-immunoprecipitation assay, we found that the interaction between CD81 and HCV E2 was interrupted by the peptide E2 (710-725). In addition, our results indicated that the synthesized peptide E2 (710-725) was not cytotoxic to hepatocytes. Taken together, our results provided novel insights into the design of anti-HCV drugs, and we suggest that the synthesized E2 (710-725) peptide is a potential candidate for use in anti-HCV therapy.

\section{Materials and methods}

Cell culture. Human hepatoma Huh7.5 cells, which were provided by Dr Charlie Rice (Rockefeller University, New York, NY, USA), were maintained in Dulbecco's modified Eagle's medium (DMEM; Invitrogen, Carlsbad, CA, USA) supplemented with $10 \%$ fetal bovine serum (FBS) (Gibco Life Technologies, Rockville, MD, USA), 2 mM L-glutamine, and $1 \%$ penicillin and streptomycin. Primary human hepatocytes $(\mathrm{pHH})$ (purchased from Lonza, Basel, Switzerland) were grown in Williams' medium E (AppliChem GmbH, Darmstadt, Germany) containing 5\% fetal calf serum, $1 \mu \mathrm{M}$ dexamethason/fortecortin, $1 \mu \mathrm{M}$ insulin, $1 \mathrm{mM}$ sodium pyruvate, $4 \mathrm{mM}$ L-glutamine, and $1 \%$ penicillin and streptomycin. All cells were cultured in a humidified atmosphere containing $5 \% \mathrm{CO}_{2}$ at $37^{\circ} \mathrm{C}$.

Peptide synthesis. The E2 (710-725) peptide representing amino acids $710-725$ of the E2 region from the HCV subtype 1a (ASWAIK WEYVV LLFLL) was synthesized by solid phase peptide synthesis, as previously described (24). The protein sequences were verified by protein sequencing (Protech, Suzhou, China).

HCVcc production. In the present study, HCVcc was produced according to a method previously described (6). Briefly, plasmid pFLJ6/JFH1 containing the full-length genomic cDNA of HCV J6 and JFH-1 was linearized and used as the template for transcription using an in vitro Megascript kit (Promega Corp., Madison, WI, USA) according to the manufacturer's instructions. Thereafter, the in vitro transcribed RNA $(25 \mu \mathrm{g})$ was delivered to Huh7.5 cells $\left(1.25 \times 10^{6}\right)$ by electroporation. After incubation for 8-12 days, the supernatants containing HCVcc were collected, filtered $(0.45 \mathrm{~mm})$, and stored at $-80^{\circ} \mathrm{C}$ for further use.

$H C V$ infection and evaluation. The viral RNA was extracted using an RNeasy Qiagen kit (Qiagen, Dusseldorf, Germany).
The viral RNA in collected supernatants was measured and normalized for equal genome equivalents which were then used to infect Huh7.5 cells and pHH in the presence or absence of synthesized peptide. After an infection of $48 \mathrm{~h}$, the cells were harvested and lysed for luciferase activity assay (Promega Corp.) according to the manufacturer's instructions. The viral RNA was extracted from the cells and quantified using reverse transcription-quantitative PCR (RT-qPCR) according to a method previously described (25). The HCV specific primers were as follows: 5'-AGCGTCTAGCCATGG CGT-3' (forward) and 5'-GGTGTACTCACCGGTTCCG-3' (reverse). The relative gene expression was obtained by normalization with GAPDH (forward, 5'-CGGATTTGGTCG TATTGG-3' and reverse, 5'-AGATGGTGATGGGATTTC-3').

Cell viability assay. Cell viability was detected by MTT assay. Briefly, cells were seeded in 96-well plates infected with HCVcc in the presence or absence of synthesized peptide. After incubation for $72 \mathrm{~h}$, the old medium was replaced by fresh medium containing $20 \mu \mathrm{l}$ MTT (Sigma-Aldrich, St. Louis, MO, USA) solution $(0.5 \mathrm{mg} / \mathrm{ml}$ diluted in PBS). After $4 \mathrm{~h}$ incubation, the medium was discarded and $150 \mu 1$ dimethyl sulfoxide was added to dissolve the formazan crystals for $15 \mathrm{~min}$. Finally, absorbance at $490 \mathrm{~nm}$ was measured using a microplate reader (Thermo Electron Corp., Vantaa, Finland).

Co-immunoprecipitation assay. Huh7.5 cells were infected with HCVcc in the presence or absence of synthesized peptide for $72 \mathrm{~h}$. Subsequently, cells were harvested and lysed in RIPA buffer (Beyotime Institute of Biotechnology, Haimen, China) containing protein inhibitor in an ice bath for $30 \mathrm{~min}$. After centrifugation at $12,000 \times \mathrm{g}$ for $30 \mathrm{~min}$, the supernatant was collected. Protein A-Sepharose beads (GE Healthcare, Piscataway, NJ, USA) mixed with a mouse monoclonal anti-CD81 antibody (sc-23962; Santa Cruz Biotechnology, Inc., Santa Cruz, CA, USA) were incubated with the lysis buffer for $1 \mathrm{~h}$ at $4^{\circ} \mathrm{C}$. Mouse monoclonal IgG antibody (sc-69786; Santa Cruz Biotechnology, Inc.) was used as control. Subsequently, the antibody-beads mixture was added to the collected supernatant and incubated for $2 \mathrm{~h}$ at $4^{\circ} \mathrm{C}$ followed by centrifugation at 3,000 $\mathrm{x}$ g for $5 \mathrm{~min}$. The bead complexes were then harvested and washed three times with lysis buffer. The protein complexes on the beads were eluted by boiling with sodium dodecyl sulfate-polyacrylamide gel electrophoresis (SDS-PAGE) sample buffer and then separated by SDS-PAGE. The target proteins were examined by western blot analysis.

Western blot analysis. Proteins were extracted from cells using a total protein extraction kit (Applygen Technologies, Inc., Beijing, China). Protein concentrations in different samples were detected using a BCA protein assay kit (Beyotime Institute of Biotechnology). Equal amounts of protein $(25 \mu \mathrm{g})$ were separated by electrophoresis on $12.5 \%$ SDS-PAGE and then transferred to nitrocellulose membranes (Miltenyi Biotec, Auburn, CA, USA). After being blocked with 3\% non-fat milk, the membranes were blotted with primary antibodies at $4^{\circ} \mathrm{C}$ overnight. Subsequently, the membranes were washed three times with Tris-buffered saline with Tween-20. The secondary antibodies conjugated with horseradish peroxidase $(1: 2,000$; BIOSS, Beijing, China) were added to the membranes and 
incubated for $1 \mathrm{~h}$ at room temperature. The band color was developed with an enhanced chemiluminescence reagent (GE Healthcare) according to the manufacturer's instructions. The band intensity was quantified with Image-Pro Plus 6.0 software (Media Cybernetics, Inc., Rockville, MD, USA). In the present study, the primary antibodies anti-HCV E2 (IT-004-005), anti-HCV non-structural protein 3 (NS3; IT-004-014), and anti-HCV NS5B (IT-004-021) were purchased from Immune Tech (New York, NY, USA); anti-CD81 (sc-9158) and anti-GAPDH (sc-25778) were purchased from Santa Cruz Biotechnology, Inc.

Statistical analysis. In the present study, all data are expressed as the means \pm standard deviation (SD). The differences were studied by one-way analysis of variance with SPSS software package version 11.5 (SPSS, Inc., Chicago, IL, USA). Finally, a $\mathrm{P}$-value $<0.05$ was considered to indicate a statistically significant difference.

\section{Results}

Synthesized peptide E2 (710-725) is not cytotoxic to cells. To explore the potential of the small molecular weight peptide E2 (710-725) from HCV E2 to act as an inhibitor of HCV infection, we first assessed the toxicity of this heterologous protein using an MTT assay. Huh7.5 cells were treated with different concentrations of E2 (710-725) $(50,100,150$ and $200 \mu \mathrm{g} / \mathrm{ml})$ for 24,48 and $72 \mathrm{~h}$. The results demonstrated that the synthesized peptide E2 (710-725) had no obvious cytotoxicity for Huh7.5 cells at any concentration (Fig. 1A). Furthermore, even with increases in time, E2 (710-725) was not cytotoxic to Huh7.5 cells (Fig. 1A). Similarly, no cytotoxic effect was observed in $\mathrm{pHH}$ treated with different concentrations of E2 (710-725) for 24,48 and $72 \mathrm{~h}$ (Fig. 1B). The data excluded the possibility that the suppression of HCVcc infection was due to toxicity of the heterologous protein.

We hypothesized that the synthesized peptide E2 (710-725) blocks the infection of HCVcc. Thus, we evaluated the effect of E2 (710-725) on the entry of HCVcc into hepatocytes. Huh7.5 cells were administrated with 50\% tissue culture infective dose (TCID50) of HCVcc plus different concentrations of the E2 (710-725) peptide. Since HCVcc carries the luciferase gene, we measured luciferase activity to assess the entry of HCVcc. The results showed that the E2 (710-725) peptide significantly inhibited luciferase activity in a dose-dependent manner in Huh7.5 cells infected with HCVcc for $72 \mathrm{~h}$ (Fig. 2A). The results were further validated using $\mathrm{pHH}$ : the luciferase activity was also dose-dependently decreased by treatment with different concentrations of E2 (710-725) peptide (Fig. 2B). These results showed that the synthesized peptide E2 (710-725) blocked the entry of HCVcc into hepatocytes.

Synthesized peptide E2 (710-725) inhibits HCV RNA and $H C V$-specific protein expression. To further validate the inhibitory effect of the E2 (710-725) peptide on HCVcc infection, we detected HCV RNA expression in the infected cells treated with different concentrations of E2 (710-725) peptide. The RT-qPCR results showed that the E2 (710-725) peptide significantly reduced intracellular HCV RNA expression in Huh7.5 (Fig. 3A) cells in a dose-dependent manner.
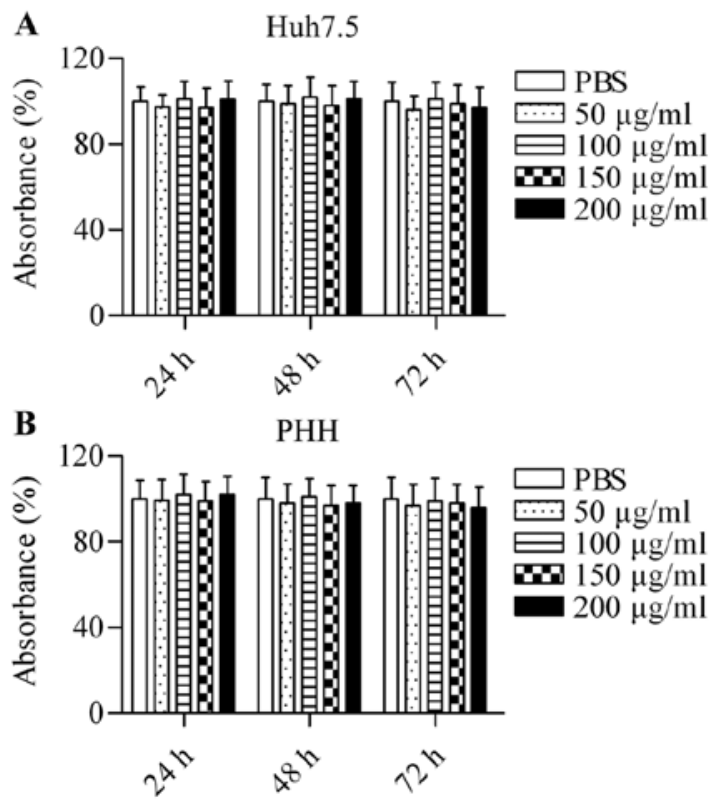

Figure 1. E2 (710-725) peptide is not cytotoxic to hepatocytes. Detection of the cytotoxicity of the synthesized peptide E2 (710-725) to Huh7.5 cells (A) and primary human hepatocytes $(\mathrm{pHH})(\mathrm{B})$ using an MTT assay. Cells were treated with different concentrations of the peptide E2 (710-725) $(50,100$, 150 and $200 \mu \mathrm{g} / \mathrm{ml}$ ) and incubated for 24,48 and $72 \mathrm{~h}$. Data are represented as the percentage of MTT reduction, assuming that the absorbance of control cells was $100 \%$. Cells treated with PBS were used as the control. Each experiment was performed in triplicate.

Furthermore, the expression level of HCV-specific proteins NS3 and NS5B was examined by western blot analysis (Fig. 3B). The results demonstrated that the protein expression of NS3 and NS5B (Fig. 3C and D) in Huh7.5 was also markedly reduced by the synthesized peptide E2 (710-725) in a dose-dependent manner. These results further confirmed that the synthesized peptide E2 (710-725) inhibited HCV infection.

Synthesized peptide E2 (710-725) attenuates the inhibitory effect of HCVcc on hepatocyte viability. To further assess the role of the synthesized peptide E2 (710-725) as an effective inhibitor of HCVcc infection, we examined its effect on cell growth arrest induced by HCVcc. The results showed that HCVcc infection significantly decreased the cell viability of Huh7.5 cells, which was then reversed by E2 (710-725) treatment in a dose-dependent manner (Fig. 4A). Moreover, the E2 (710-725) peptide also significantly attenuated the inhibition of hepatocyte viability induced by HCVcc infection in $\mathrm{pHH}$ in a dose-dependent manner (Fig. 4B). In summary, our data suggested that the synthesized peptide E2 (710-725) effectively blocked HCVcc infection. In order to gain a better understanding of the underlying mechanism of the E2 (710-725) peptide in preventing HCVcc infection, we performed subsequent experiments.

We hypothesized that the synthesized peptide E2 (710-725) abrogates the interaction between CD81 and HCV E2 envelope protein. CD81 has been suggested to act as an essential $\mathrm{HCV}$ receptor that interacts with HCV E2 envelope protein for subsequent HCV entry $(10,26)$. In order to investigate whether the E2 (710-725) peptide derived from the HCV E2 protein blocked interaction between CD81 and the HCV E2 protein, 

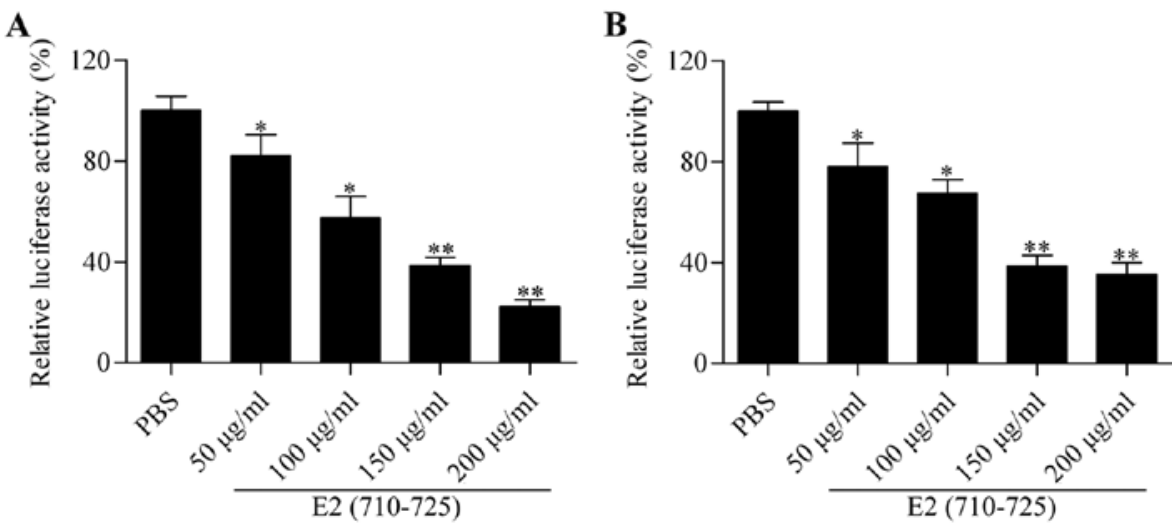

Figure 2. E2 (710-725) peptide blocks the entry of cell culture-derived HCV (HCVcc). Detection of the effect of E2 (710-725) on the luciferase activity in Huh7.5 (A) and primary human hepatocytes (pHH) (B) cells infected with HCVcc. After incubation with different concentrations of E2 (710-725) peptide for $72 \mathrm{~h}$, cells were harvested, lysed and detected using luciferase activity assay. ${ }^{*} \mathrm{p}<0.05,{ }^{* *} \mathrm{p}<0.01 \mathrm{vs}$. PBS.

A

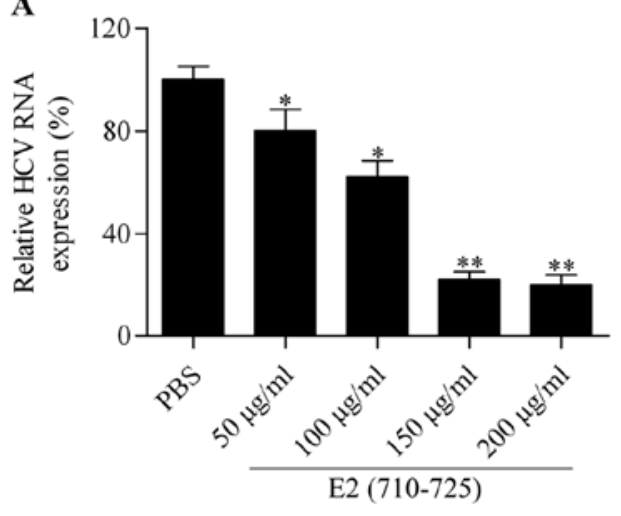

B

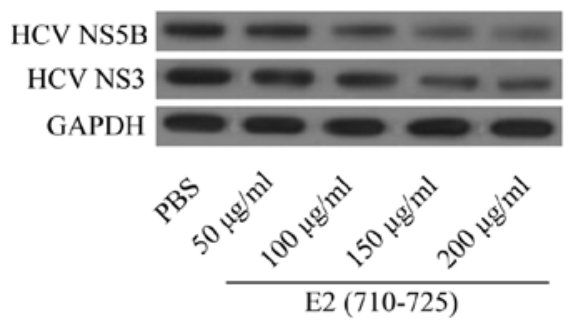

C
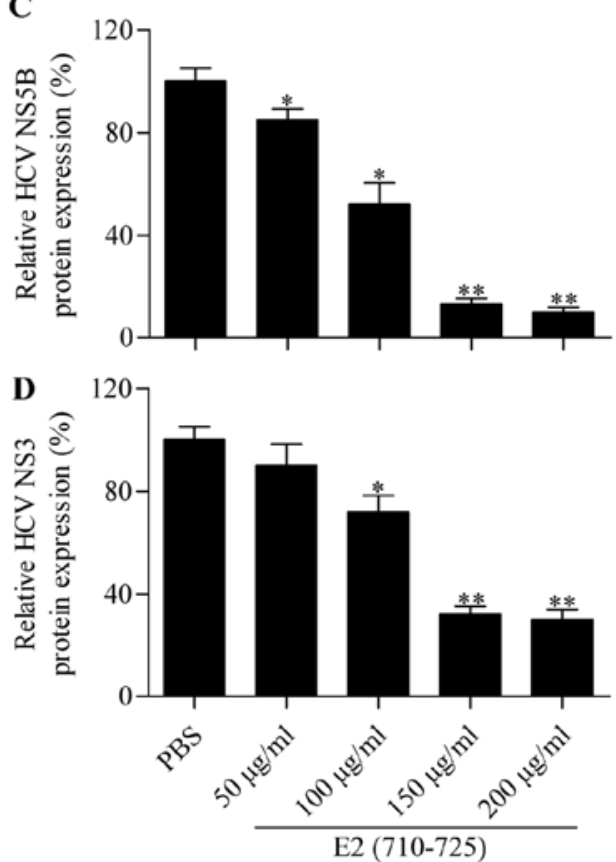

Figure 3. E2 (710-725) peptide reduces cell culture-derived hepatitis C virus (HCVcc) infection. (A) RT-qPCR analysis of HCV RNA expression in Huh7.5 cells. Cells were infected with HCVcc plus different concentrations of the E2 (710-725) peptide for $72 \mathrm{~h}$ before they were harvested for analysis.(B) Western blot analysis of the expression of non-structural protein 5B (NS5B) and non-structural protein 3 (NS3) proteins in Huh7.5 cells. The relative protein expression level of NS5B (C) and NS3 (D) was quantified with Image-Pro Plus 6.0 software and normalized to GAPDH. $n=3$ independent experiments; ${ }^{*}$ p $<0.05,{ }^{* *}$ p $<0.01$ vs. PBS.

we performed a co-immunoprecipitation assay. Thus, using the CD81 antibody, we analyzed HCV E2 protein expression in the immune complex by western blot analysis. The results showed that HCV E2 protein expression was significantly reduced in the immune complex from cells treated with E2 (710-725) whereas CD81 protein expression level was barely altered (Fig. 5). The results suggested that E2 (710-725) competitively binds to CD81, and thus interrupted the interaction between CD81 and HCV E2 envelope protein by which E2 (710-725) blocked HCV cell entry.

\section{Discussion}

In the present study, we demonstrated that the synthesized peptide E2 (710-725) markedly inhibited HCV infection, possibly due to its ability to disrupt the interaction between the HCV E2 envelope protein and CD81 receptor. The results suggest that the segment from 710-725 amino acid residues of E2 plays an important role in regulating HCV entry.

Previous research has proposed that the HCV E2 envelope protein plays a major role in regulating HCV entry into cells (7). It has been reported that W420, Y527, W529, G530 and D535 in the $\mathrm{E} 2$ protein are the critical binding sites for the CD81 receptor (27). The E2 (436-443) motif plays an important role in viral entry in a CD81-dependent manner (28). The conserved E2 (502-520) segment has been suggested to play a critical role in cell entry by influencing the interaction with $\mathrm{HCV}$ receptors (14). Mutations of the two conserved histidines (490 and 621) located in E2 have been shown to block the binding of CD81 with the E2 protein (16). Albecka et al have demonstrated that a segment 

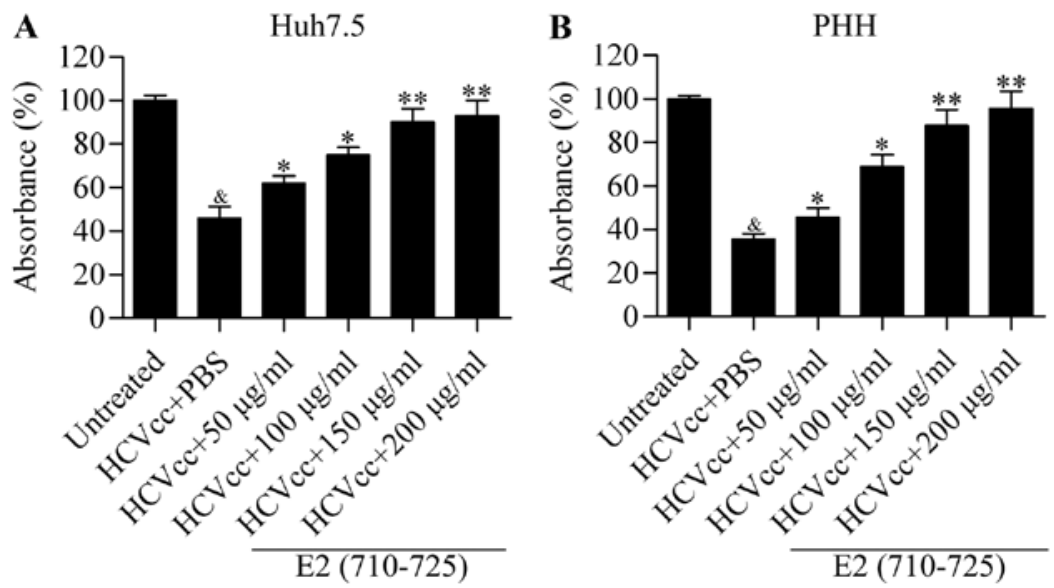

Figure 4. E2 (710-725) peptide maintains cell viability in response to hepatitis C virus (HCV) infection. We detected cell viability of Huh7.5 cells (A) and primary human hepatocytes (pHH) (B) with an MTT assay. Cells infected with HCVcc were treated with different concentrations of the peptide E2 (710-725) $(50,100,150$ and $200 \mu \mathrm{g} / \mathrm{ml})$ for $72 \mathrm{~h}$. Results were expressed as the percentage of MTT reduction, assuming that the absorbance of the control cells was $100 \%$. Untreated cells were used as the control. Each experiment was performed in triplicate. ${ }^{k} \mathrm{p}<0.01$ vs. untreated; ${ }^{*} \mathrm{p}<0.05,{ }^{* *} \mathrm{p}<0.01 \mathrm{vs}$. HCVcc+PBS.
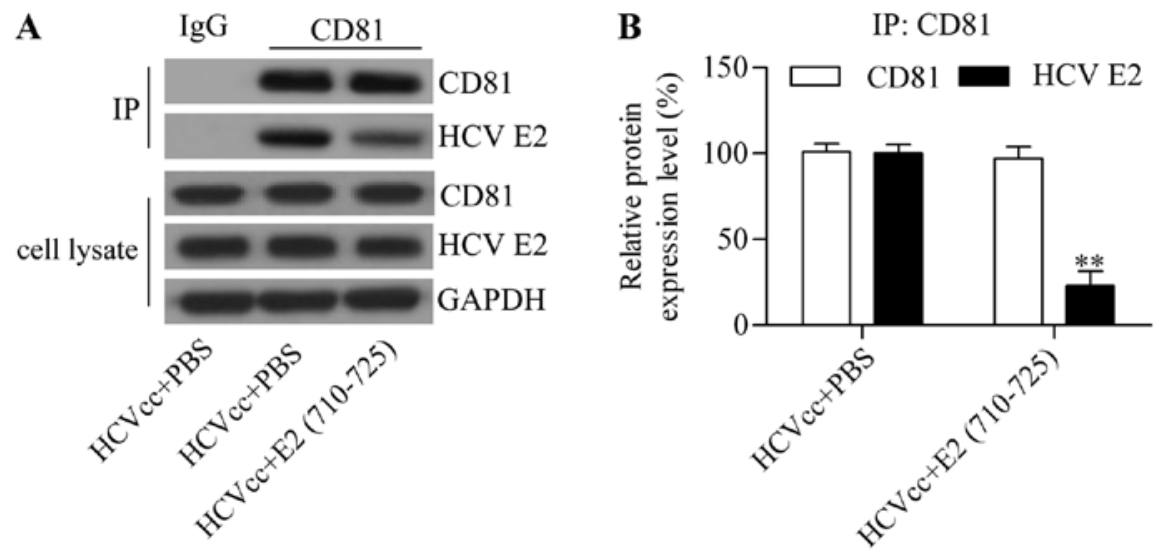

Figure 5. E2 (710-725) peptide blocks the interaction between CD81 and hepatitis C virus (HCV) E2 envelope protein. (A) Detection of the protein expression in the co-immunoprecipitation complex by western blot analysis with indicated antibodies. Huh7.5 infected with cell culture-derived HCV (HCVec) were treated with $200 \mu \mathrm{g} / \mathrm{ml}$ of E2 (710-725) peptide for $24 \mathrm{~h}$. Cells were then harvested, lysed, and prepared for immunoprecipitation with anti-CD81 antibody. IgG antibody was used as the control bait antibody. (B) The relative protein expression level of CD81 and E2 in the immune complex was measured with Image-Pro Plus 6.0 software and normalized to GAPDH. ${ }^{*} \mathrm{p}<0.01$.

from 705 to 715 located in the stem region of E2 is involved in regulating HCV entry and infection (17). However, the majority of studies have focused on the N-terminal and core region of E2 $(27,28)$. It remains largely unknown whether the amino acid sites located in the carboxyl terminus of E2 play a role in regulating $\mathrm{HCV}$ entry. In the present study, we synthesized a peptide from 710-725 amino acids of E2 and investigated its effect on HCV infection. We observed that the E2 (710-725) peptide blocked HCV infection in both human hepatoma Huh7.5 cells and also pHH. Our data suggest that the amino acid residues in the carboxyl-terminal of the HCV E2 protein also play an important role in terms of regulating $\mathrm{HCV}$ infection.

To date, various cell surface receptors have been identified as $\mathrm{HCV}$ entry receptors, including CD81, low-density lipoprotein receptor, SR-BI, claudin 1 and occludin $(8,9)$. Of these receptors, CD81 is the first identified $\mathrm{HCV}$ receptor which interacts with the HCV E2 protein to facilitate the endocytosis of HCV $(10,11)$. Numerous studies have aimed to target CD81 to block HCV infection $(12,29-31)$. It has previously been reported that blocking CD81 using anti-CD81 monoclonal antibodies dose-dependently inhibited HCV entry $(12,29)$. Furthermore, treatment with anti-CD81 monoclonal antibodies has been noted to effectively prevent $\mathrm{HCV}$ infection and spread in chimeric mice with human liver (30). Notably, the silencing of CD81 by small interfering RNA significantly suppressed HCV pseudotype infection in Huh7.5 hepatoma cells, whereas overexpression of CD81 in infection-resistant human liver cells promoted HCV infection (29). More recently, it has been reported that microRNA-194 functions as a hepatocyte gatekeeper that blocks HCV entry by targeting and inhibiting CD81 expression (31). Additionally, it has also been suggested that CD81 plays an important role in HCV replication (32). Cells exhibiting low expression of CD81 had limited replication capacity, which was restored by overexpression of CD81 (32). In the present study, we demonstrated that the E2 (710-725) peptide is capable of blocking the interaction between CD81 and the HCV E2 protein, and this leads to inhibition of $\mathrm{HCV}$ entry and infection. 
The potential use of synthesized peptides to treat $\mathrm{HCV}$ infection has previously been studied. For example, Krepstakies et al have reported that synthetic anti-lipopolysaccharide peptides bind to heparan sulfate moieties on the cell surface and inhibit HCV infection (18). It has also been noted that the human apolipoprotein E peptide directly blocked the binding of HCV to hepatocytes (19). A human radixin hinge region peptide has been demonstrated to inhibit HCV infection through disrupting HCV engagement of CD81 (20). Interestingly, a synthesized peptide C18 (WPWHNHR) with the highest affinity for binding HCV E2 protein has been demonstrated to be capable of inhibiting HCV infection (21). In the present study, we detected the effect of the synthesized peptide from HCV E2 glycoprotein and observed that this peptide blocked HCV cell entry and also inhibited HCV infection. Our results indicated that the synthesized E2 (710-725) peptide serves as a potential candidate for anti-HCV therapy.

Previous research has focused on HCV E2 in order to develop new and potentially therapeutic drugs for the treatment of HCV infection. For instance, it was previously noted that blocking the signaling lymphocytic activation molecule family 3 expression on the hepatocytes by specific antibody abrogated its interaction with HCV E2, thus leading to the inhibition of HCV entry (33). A new compound, 281816, has been screened using surface plasmon resonance detection, which binds the HCV E2 protein and blocks E2 binding to CD81 and inhibits HCV infection (34). In the present study, we demonstrated that the peptide E2 (710-725) derived from the HCV E2 protein acted as an inhibitor of HCV E2 entry, and we also provided useful insights which should be utilized to fiurther the development of new drugs for preventing HCV infection. Moreover, we confirmed that the synthesized peptide E2 (710-725) exerted no cytotoxicity and has the potential to be used for the treatment of $\mathrm{HCV}$ infection. However, further studies are needed to investigate its safety and effectiveness using in vivo animal models.

\section{Acknowledgements}

The present study was supported by a grant from the National Natural Science Foundation of China (no. 81170394).

\section{References}

1. Wasley A and Alter MJ: Epidemiology of hepatitis C: Geographic differences and temporal trends. Semin Liver Dis 20: 1-16, 2000

2. Keck ZY, Li TK, Xia J, Bartosch B, Cosset FL, Dubuisson J and Foung SK: Analysis of a highly flexible conformational immunogenic domain a in hepatitis C virus E2. J Virol 79: 13199-13208, 2005.

3. Jacobson IM, Gordon SC, Kowdley KV, Yoshida EM, RodriguezTorres M, Sulkowski MS, Shiffman ML, Lawitz E, Everson G, Bennett M, et al; POSITRON Study; FUSION Study: Sofosbuvir for hepatitis $\mathrm{C}$ genotype 2 or 3 in patients without treatment options. N Engl J Med 368: 1867-1877, 2013.

4. Zeuzem S, Dusheiko GM, Salupere R, Mangia A, Flisiak R, Hyland RH, Illeperuma A, Svarovskaia E, Brainard DM, Symonds WT, et al; VALENCE Investigators: Sofosbuvir and ribavirin in $\mathrm{HCV}$ genotypes 2 and 3. N Engl $\mathbf{J}$ Med 370 1993-2001, 2014.

5. Carrère-Kremer $\mathrm{S}$, Montpellier $\mathrm{C}$, Lorenzo L, Brulin B, Cocquerel L, Belouzard S, Penin F and Dubuisson J: Regulation of hepatitis $\mathrm{C}$ virus polyprotein processing by signal peptidase involves structural determinants at the $\mathrm{p} 7$ sequence junctions. J Biol Chem 279: 41384-41392, 2004.
6. Lindenbach BD, Evans MJ, Syder AJ, Wölk B, Tellinghuisen TL, Liu CC, Maruyama T, Hynes RO, Burton DR, McKeating JA, and Rice CM: Complete replication of hepatitis $\mathrm{C}$ virus in cell culture. Science 309: 623-626, 2005

7. Khan AG, Miller MT and Marcotrigiano J: HCV glycoprotein structures: what to expect from the unexpected. Curr Opin Virol 12: 53-58, 2015.

8. Dorner M, Horwitz JA, Robbins JB, Barry WT, Feng Q, Mu K Jones CT, Schoggins JW, Catanese MT, Burton DR, et al: A genetically humanized mouse model for hepatitis $\mathrm{C}$ virus infection. Nature 474: 208-211, 2011.

9. Meredith LW, Wilson GK, Fletcher NF and McKeating JA: Hepatitis C virus entry: beyond receptors. Rev Med Virol 22: 182-193, 2012.

10. Pileri P, Uematsu Y, Campagnoli S, Galli G, Falugi F, Petracca R, Weiner AJ, Houghton M, Rosa D, Grandi G and Abrignani S: Binding of hepatitis C virus to CD81. Science 282: 938-941, 1998.

11. Bartosch B, Dubuisson J and Cosset FL: Infectious hepatitis C virus pseudo-particles containing functional E1-E2 envelope protein complexes. J Exp Med 197: 633-642, 2003.

12. Molina S, Castet V, Pichard-Garcia L, Wychowski C, Meurs E, Pascussi JM, Sureau C, Fabre JM, Sacunha A, Larrey D, et al: Serum-derived hepatitis $C$ virus infection of primary human hepatocytes is tetraspanin CD81 dependent. J Virol 82: 569-574, 2008.

13. Meuleman P, Hesselgesser J, Paulson M, Vanwolleghem T, Desombere I, Reiser H and Leroux-Roels G: Anti-CD81 antibodies can prevent a hepatitis $\mathrm{C}$ virus infection in vivo. Hepatology 48: 1761-1768, 2008.

14. Lavie M, Sarrazin S, Montserret R, Descamps V, Baumert TF, Duverlie G, Séron K, Penin F and Dubuisson J: Identification of conserved residues in hepatitis $\mathrm{C}$ virus envelope glycoprotein E2 that modulate virus dependence on CD81 and SRB1 entry factors. J Virol 88: 10584-10597, 2014.

15. Keck ZY, Angus AG, Wang W, Lau P, Wang Y, Gatherer D, Patel AH and Foung SK: Non-random escape pathways from a broadly neutralizing human monoclonal antibody map to a highly conserved region on the hepatitis $\mathrm{C}$ virus $\mathrm{E} 2$ glycoprotein encompassing amino acids 412-423. PLoS Pathog 10: e1004297, 2014.

16. Qin ZL, Ju HP, Gao TT, Wang WB, Ren H, Zhao P and Qi ZT: Two conserved histidines (His490 and His621) on the E2 glycoprotein of hepatitis $\mathrm{C}$ virus are critical for CD81-mediated cell entry. J Gen Virol 96: 1389-1399, 2015.

17. Albecka A, Montserret R, Krey T, Tarr AW, Diesis E, Ball JK, Descamps V, Duverlie G, Rey F, Penin F and Dubuisson J: Identification of new functional regions in hepatitis $\mathrm{C}$ virus envelope glycoprotein E2. J Virol 85: 1777-1792, 2011.

18. Krepstakies M, Lucifora J, Nagel CH, Zeisel MB, Holstermann B, Hohenberg H, Kowalski I, Gutsmann T, Baumert TF, Brandenburg K, et al: A new class of synthetic peptide inhibitors blocks attachment and entry of human pathogenic viruses. J Infect Dis 205: 1654-1664, 2012.

19. Liu S, McCormick KD, Zhao W, Zhao T, Fan D and Wang T: Human apolipoprotein E peptides inhibit hepatitis $\mathrm{C}$ virus entry by blocking virus binding. Hepatology 56: 484-491, 2012.

20. Bukong TN, Kodys K and Szabo G: A novel human radixin peptide inhibits hepatitis $C$ virus infection at the level of cell entry. Int J Pept Res Ther 20: 269-276, 2014.

21. Lü X, Yao M, Zhang JM, Yang J, Lei YF, Huang XJ, Jia ZS, Ma L, Lan HY, Xu ZK and Yin W: Identification of peptides that bind hepatitis $\mathrm{C}$ virus envelope protein $\mathrm{E} 2$ and inhibit viral cellular entry from a phage-display peptide library. Int J Mol Med 33: 1312-1318, 2014.

22. Wakita T, Pietschmann T, Kato T, Date T, Miyamoto M, Zhao Z, Murthy K, Habermann A, Kräusslich HG, Mizokami M, et al: Production of infectious hepatitis $C$ virus in tissue culture from a cloned viral genome. Nat Med 11: 791-796, 2005.

23. Zhong J, Gastaminza P, Cheng G, Kapadia S, Kato T, Burton DR, Wieland SF, Uprichard SL, Wakita T and Chisari FV: Robust hepatitis C virus infection in vitro. Proc Natl Acad Sci USA 102: 9294-9299, 2005.

24. Blanco-Canosa JB and Dawson PE: An efficient Fmoc-SPPS approach for the generation of thioester peptide precursors for use in native chemical ligation. Angew Chem Int Ed Engl 47: 6851-6855, 2008.

25. Alsaleh K, Delavalle PY, Pillez A, Duverlie G, Descamps V, Rouillé Y, Dubuisson J and Wychowski C: Identification of basic amino acids at the $\mathrm{N}$-terminal end of the core protein that are crucial for hepatitis C virus infectivity. J Virol 84: 12515-12528, 2010. 
26. Krieger SE, Zeisel MB, Davis C, Thumann C, Harris HJ, Schnober EK, Mee C, Soulier E, Royer C, Lambotin M, et al Inhibition of hepatitis $\mathrm{C}$ virus infection by anti-claudin-1 antibodies is mediated by neutralization of E2-CD81-claudin-1 associations. Hepatology 51: 1144-1157, 2010.

27. Owsianka AM, Timms JM, Tarr AW, Brown RJ, Hickling TP, Szwejk A, Bienkowska-Szewczyk K, Thomson BJ, Patel AH and Ball JK: Identification of conserved residues in the E2 envelope glycoprotein of the hepatitis $\mathrm{C}$ virus that are critical for CD81 binding. J Virol 80: 8695-8704, 2006.

28. Drummer HE, Boo I, Maerz AL and Poumbourios P: A conserved Gly436-Trp-Leu-Ala-Gly-Leu-Phe-Tyr motif in hepatitis C virus glycoprotein E2 is a determinant of CD81 binding and viral entry. J Virol 80: 7844-7853, 2006.

29. Zhang J, Randall G, Higginbottom A, Monk P, Rice CM and McKeating JA: CD81 is required for hepatitis C virus glycoprotein-mediated viral infection. J Virol 78: 1448-1455, 2004.

30. Ji C, Liu Y, Pamulapati C, Bohini S, Fertig G, Schraeml M, Rubas W, Brandt M, Ries S, Ma H and Klumpp K: Prevention of hepatitis $C$ virus infection and spread in human liver chimeric mice by an anti-CD81 monoclonal antibody. Hepatology 61: $1136-1144,2015$.
31. Mekky RY, El-Ekiaby NM, Hamza MT, Elemam NM, El-Sayed M,Esmat G and Abdelaziz AI: Mir-194 is a hepatocyte gate keeper hindering HCV entry through targeting CD81 receptor. J Infect 70: 78-87, 2015.

32. Zhang YY, Zhang BH, Ishii K and Liang TJ: Novel function of CD81 in controlling hepatitis $\mathrm{C}$ virus replication. J Virol 84: 3396-3407, 2010.

33. Cartier F, Marcq I, Douam F, Ossart C, Regnier A, Debuysscher V, Lavillette D and Bouhlal $\mathrm{H}$ : The expression of the hepatocyte SLAMF3 (CD229) receptor enhances the hepatitis C virus infection. PLoS One 9: e99601, 2014.

34. Al Olaby RR, Cocquerel L, Zemla A, Saas L, Dubuisson J, Vielmetter J, Marcotrigiano J, Khan AG, Vences Catalan F, Perryman AL, et al: Identification of a novel drug lead that inhibits HCV infection and cell-to-cell transmission by targeting the HCV E2 glycoprotein. PLoS One 9: e111333, 2014. 